\title{
Serotonin Receptors for Treatment of Insomnia
}

\author{
Jieon Lee ${ }^{1,2}$ and Hyunah Choo ${ }^{1,2}$ \\ 'Division of Bio-Medical Science \& Technology, KIST School, Korea University of Science and Technology, Seoul, Korea \\ ${ }^{2}$ Center for Neuro-Medicine, Brain Research Institute, Korea Institute of Science and Technology, Seoul, Korea
}

Insomnia is characterized by complaints about sleep such as difficulty in falling asleep, abnormality in sleep architecture, and reduction in total sleep time, resulting in serious impairments in daytime activities. It has been suggested that insomnia usually has comorbity with medical and psychiatric disorders including anxiety, depression, and substance misuse disorders, which could be a risk factor for new onset psychiatric disorders. Though there are a number of drugs targeting various receptors such as zolpidem (a benzodiazepine receptor agonist), zaleplon (a anonbenzodiazepine modulator of GABA-A receptor), and ramelteon (a melatonin receptor agonist), these medications do not completely cure insomnia and have a variety of side effects. Currently, trazodone, a 5- $\mathrm{HT}_{2 \mathrm{~A}}$ receptor antagonist, was widely prescribed as sleep aids in the United States without FDA indication for insomnia and recent studies have also shown that lumateperone as $5-\mathrm{HT}_{2 \mathrm{~A}}$ receptor antagonist improve the quality of sleep. Additionally, it has been proposed that $5-\mathrm{HT}_{7}$ receptor is involved in regulation of sleep-wake cycle. 5 - $\mathrm{HT}_{7}$ receptor modulators, such as SB-269970, LP-44, JNJ-18038683, and a $\beta$-arrestin biased ligand altered sleep parameters. Therefore, serotonin receptors could be powerful targets for treatment of insomnia.

Key Words: Insomnia; Serotonin receptor; Trazodone; Lumateperone

Received: December 17, 2018 Revised: February 21, 2019 Accepted: February 24, 2019

Corresponding author: Hyunah Choo, PhD, Center for Neuro-Medicine, Korea Institute of Science and Technology, Hwarangro 14-gil-5, Seoul 136-791, Korea. Tel: 82-2-958-5157, Fax: 82-2-958-5189, E-mail: hchoo@kist.re.kr

(a) This is an Open Access article distributed under the terms of the Creative Commons Attribution Non-Commercial License (https://creativecommons.org/licenses/by$\mathrm{nc} / 4.0$ ) which permits unrestricted non-commercial use, distribution, and reproduction in any medium, provided the original work is properly cited.

\section{INTRODUCTION}

Sleep disorder is a medical disorder of the sleep patterns of a person and involves problems including snoring, sleep apnea, insomnia, and sleep deprivation, which can affect an individual's health, safety and quality of life [1]. Among these types of sleep disorders, insomnia is the most common disorder characterized by symptoms such as difficulty in falling asleep and/or staying asleep, and abnormalities in quality and quantity of sleep, resulting in serious impairments in daytime activities, such as fatigue, difficulties with cognitive functions, and mood disturbances during wakefulness $[1,2]$. Insomnia has been categorized as primary (idiopathic) and secondary (comorbid) insomnia [3], depending on whether the condition of insomnia is attributable to other medical or psychiatric disorders by the Diagnostic and Statistical Manual for Mental Disorders 4th edition (DSM-IV) [4] and International Classification of Sleep Disorders: Diagnostic and Coding Manual 2nd edition (ICSD-2) [5]. The DSM-V [6], however, proposed on the importance of comorbid nature of insomnia and calls for treatment of both insomnia and the medical disorder [7].
The US National Comorbidity Survey showed that there is a high rate of comorbidity between insomnia and medical and psychiatric disorders such as anxiety, depression, and substance misuse disorders [8]. Also, in longitudinal studies about insomnia [9], they suggested that it could be a risk factor for new onset psychiatric disorders. Breslau et al. [10] and Roth et al. [9] reported that individuals with insomnia were four times more likely to develop new major depression over the next 3-5 years than were individuals without insomnia.

The treatment of insomnia includes cognitive behavioral therapy (CBT), medication, or a combination of both [3]. In the case of acute insomnia, pharmacological treatment is mainly performed, and in the case of chronic insomnia, CBT such as sleep restriction, stimulus control, relaxation, and cognitive strategy is recommended $[2,10]$. However, according to 2005 US National Institutes of Health state of the science conference on insomnia, both the treatment modalities of CBT and pharmacotherapy are more effective in managing chronic insomnia than monotherapy of CBT [11]. Hypnotic agents approved by the US Food and Drug Administration (FDA) for the treatment of insomnia include bezo- 
diazepine receptor agonists (zolpidem, estazolam, and triazolam), nonbenzodiazepine modulators of gamma aminobutyric acid-A (GABA-A) receptors (esxopiclone and zaleplon), antihistamine drugs (hydroxyzine and diphenhydramine), a tricyclic drug (doxepin), and a melatonin receptor agonist (ramelteon) [1,12] (Table 1). Another drugs to improve symptoms of insomnia approved by the FDA are barbiturates (secobarbital and butalbital), but they are not recommended because of potential toxicity $[1,12,13]$. In addition, there are a number of drugs without FDA indication for insomnia, including sedating antidepressants (e.g., trazodone, mirtazpine, and nefazodone) that are sometimes used to treat comorbid depression patients with insomnia [13]. Several serotonin 5- $\mathrm{HT}_{2}$ receptor antagonists also provide favorable effects on depression and insomnia by increasing slow wave sleep (SWS) and decreasing waking after sleep onset $[7,14]$. Serotonin $(5-H T)$ within central nervous system contributes to numerous physiological functions including sleep-wake behavior, cognition, circadian rhythm, pain, and depression. 5-HT receptor can be classified into fifteen 5-HT receptor subtypes, which mediate all of these physiological processes [15-17]. The role of 5-HT in sleep regulation has been extensively studied and many studies proposed that 5-HT participates in promotion of wakefulness (W) and regulation of rapid eye movement (REM) sleep [16]. Trazodone (Figure 1) belongs to $5-\mathrm{HT}_{2 \mathrm{~A}}$ receptor antagonists and acts as an $\alpha 1$ adrenergic receptor antagonist and as an inhibitor of serotonin transporter (SERT), indicating efficacy for insomnia $[18,19]$. One of $5-\mathrm{HT}_{2 \mathrm{~A}}$ receptor antagonists, lumateperone (ITI-007) (Figure 1) behaves as a dopamine receptor modulator and a serotonin transporter inhibitor and improves quality of sleep [20,21]. Hagan et al. [22] demonstrated that a $5-\mathrm{HT}_{7}$ receptor antagonist, SB-269970 (Figure 2) increased the latency to REM sleep and decreased the total duration in REM sleep. There is a further investigation that $5-\mathrm{HT}_{7}$ receptor knock-out mice spent less time in REM sleep than wild-type mice [23]. LP-44 [24] (Figure 2), a 5- $\mathrm{HT}_{7}$ receptor agonist, was studied for effects on sleep in rats. Administration of LP44 into dorsal raphe nucleus (DRN) induced decrease in REM sleep and the number of REM periods [25]. Bonaventure et al. [26] reported that the preclinical and clinical research of $5-\mathrm{HT}_{7}$ receptor antagonist, JNJ-18038683 (Figure 2) leads to dose-dependently suppress REM sleep and increase REM sleep latency after the treatment. Kim et al. [27] have discovered selective $\beta$ arrestin biased ligand against $5-\mathrm{HT}_{7}$ receptor (Figure 2), which increased non-REM (NREM) sleep duration unlike a balanced antagonist SB-269970. In this review, we focus on the role of serotonin (5-HT) receptor in insomnia and effects of the related drugs on sleep.

\section{5-HT 2 RECEPTOR FOR INSOMNIA}

One of serotonin receptors, $5-\mathrm{HT}_{2}$ receptor is comprised of $5-\mathrm{HT}_{2 \mathrm{~A}}, 5-\mathrm{HT}_{2 \mathrm{~B}}$, and 5- $\mathrm{HT}_{2 \mathrm{C}}$ receptor subtypes [28,29]. According to autoradiographical and immunohistochemical studies, these $5-\mathrm{HT}_{2}$ receptors are distributed in specific area of the brain.
5- $\mathrm{HT}_{2 \mathrm{~A}}$ receptors are located in basal fore brain, ventral tegmental area, and median raphe nuclei linked to the promotion of the waking state $[29,30]$. Several studies have shown that $5-\mathrm{HT}_{2}$ receptor is responsible for the regulation of SWS in human and animals [24, 28]. 5- $\mathrm{HT}_{2 \mathrm{~A}}$ receptor knock-out mice showed an increase of $\mathrm{W}$ and a decrease of NREM sleep. Values of REM sleep were not altered by genotype [31]. Dugovic and Waquier [32] reported that multiple $5-\mathrm{HT}_{2}$ receptor antagonists induced increase of SWS in rodents, but drugs with $5-\mathrm{HT}_{2}$ receptor agonism decreased SWS $[29,30]$. A 5- $\mathrm{HT}_{2 \mathrm{~A}}$ receptor antagonist, trazodone (Figure 1) might be a useful drug to reduce perceived sleep disturbances because people who is suffering from insomnia have reduced pattern of SWS [33-35]. Although the FDA confirmed that trazodone was effective against depression not insomnia, it was recently prescribed as a sleep aid [34]. Trazodone has potent binding property of 5- $\mathrm{HT}_{2 \mathrm{~A}}$ receptor with antagonism and acts as an inhibitor of SERT, as well as antagonist of $\alpha 1$ adrenergic receptor and $\mathrm{H} 1$ histamine receptor. When $5-\mathrm{HT}_{2 \mathrm{~A}}$ receptor is over-saturated by the range of 25-100 $\mathrm{mg}$ doses of trazodone, al adrenergic receptor and $\mathrm{H} 1$ histamine receptor are simultaneously blocked, recruiting the hypnotic actions which promote sleep onset and maintain sleep [20]. Inhibition of these neurotransmitter systems involved in the arousal mechanism can impair arousal and induce sleep maintenance without causing tolerance [20]. There are a number of reports that clinical trials of trazodone are conducted to evaluate effectiveness in the treatment of insomnia. In order to examine the hypnotic efficacy and daytime effects of trazodone, Nierenberg et al. [36] and Roth et al. [37] conducted clinical trials on patients with primary insomnia. After administration of trazodone for a week, the results showed that total awakenings were significantly decreased and SWS time was increased, without change in sleep latency and REM latency, and REM sleep [36,38]. Consequently, it has been concluded that trazodone had an improved effect on insomnia compared with placebo [37]. Muratatorio et al. [38] performed a polysomnographic study of patients with depression and insomnia treated with trazodone. In this study, it seems that trazodone is effective in alleviating depression symptoms and improving insomnia. Roth et al. [37] used overnight polysomnography and modified Multiple Sleep Latency Tests to assess the quality of sleep for trazodone. Their polysomnographic data showed that night-time awakenings and perceived sleep difficulty are improved after low dose $(50 \mathrm{mg})$ trazodone, and trazodone also increases SWS in primary insomnia [37]. Thus, these results are consistent with previous findings of trazodone's effects on sleep quality $[39,40]$. Since sleep disturbances seen in depression are a side effect of antidepressants, a number of depressive patients who are taking selective serotonin reuptake inhibitors (SSRIs) are suffering from insomnia. Therefore, Kaynak and his colleuges [41] assessed the effects of trazodone on depressive patients with insomnia treated with SSRIs. They administered $100 \mathrm{mg}$ trazodone or placebo for a week to subjects who had been treated with SSRIs for at least 3 weeks and measured the quality of sleep with using polysomnographic recordings after treatment with 
Table 1. Medications for treatment of insomnia $[1,12]$ Class Drug and Features Estazolam<smiles>Clc1ccc2c(c1)C(c1ccccc1)=NCc1nncn1-2</smiles>

Benzodiazepines

No CYP-related drug interactions

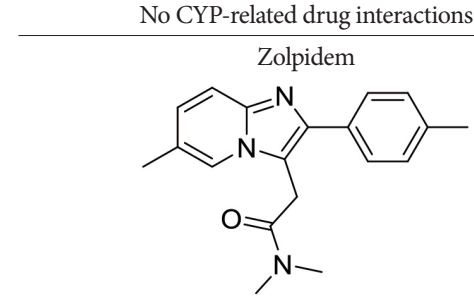

Most widely prescribed hypnotic

Esxopiclone (eszopiclone)

GABA-A

receptor modulators

(nonbenzodiazepines)

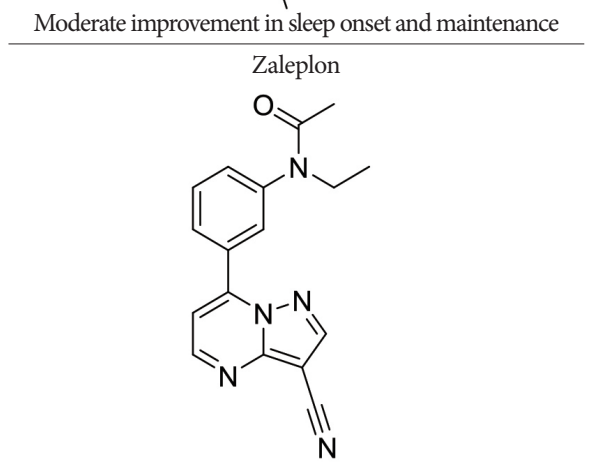

Ultra-short elimination of half life

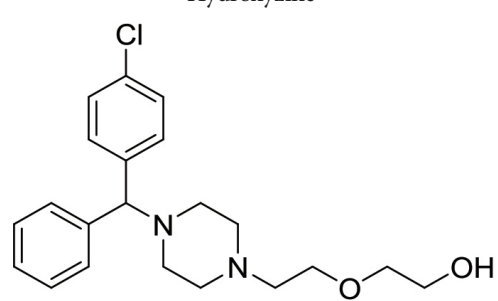

Antihistamine drug

Treatment of itchiness, anxiety, and psychoneurosis<smiles>CN(C)CCOC(c1ccccc1)c1ccccc1</smiles>

Treatment of insomnia and common cold, widely used in nonprescription sleep aid

Table 1. Medications for treatment of insomnia [1,12] (continued)

Class

Drug and Features

Doxepin

Tricyclic drug<smiles>CN(C)CC/C=C1\c2ccccc2COc2ccccc21</smiles>

Treatment of major depressive disorder, anxiety disorder, and insomnia

Ramelteon

Melatonin receptor agonist

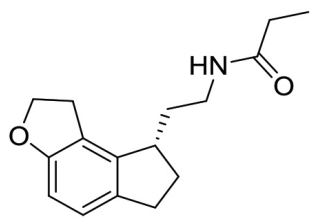

No appreciable affinity for other receptors<smiles>C=CCCC1(C(C)CCC)C(=O)NC(=O)NC1=O</smiles>

Temporary treatment of insomnia

Barbiturates<smiles>C=CCC1(CC(C)Br)C(=O)NC(=O)NC1=O</smiles>

Cause dependence or addiction Trazodone

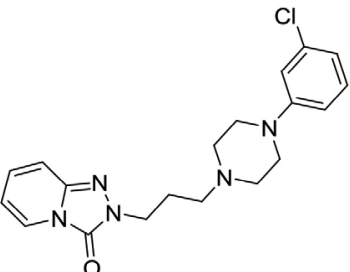

An alternative to benzodiazepines for the treatment of insomnia

Sedating antidepressant<smiles>CN1CCN2c3ncccc3Cc3ccccc3C2C1</smiles>

Reduction the time to fall asleep and increase in the quality of sleep in patients with sleep disorder caused by depression

Nefazodone

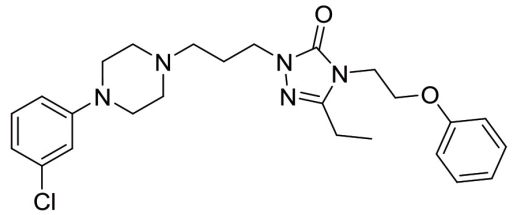

Potent inhibitor of CYP3A4 


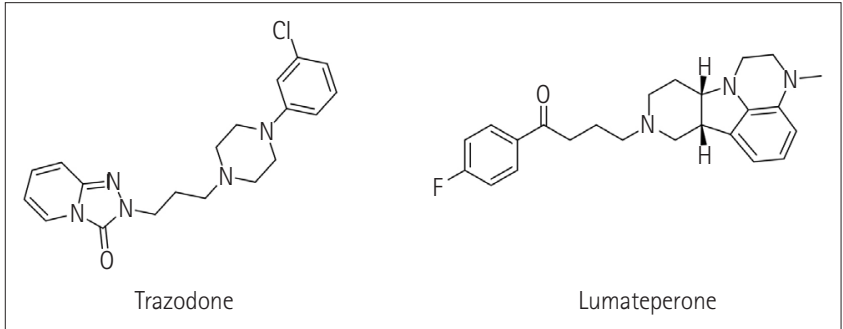

Figure 1. Structures of 5- $\mathrm{HT}_{2 \mathrm{~A}}$ receptor antagonists.

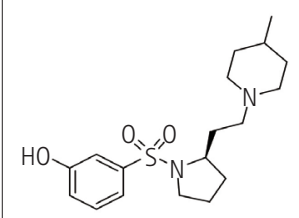

SB-269970 $5-\mathrm{HT}_{7} \mathrm{R}, \mathrm{K}_{\mathrm{i}}=1.26 \mathrm{nM}$

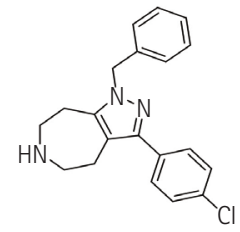

JNJ-18038683

$5-\mathrm{HT}_{7} \mathrm{R}_{1} \mathrm{~K}=6.5 \mathrm{nM}$

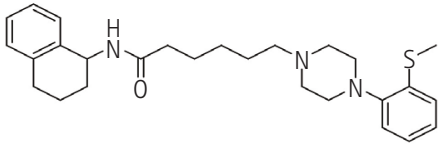

$\mathrm{LP}-44$ $5-\mathrm{HT}_{7} \mathrm{R}, \mathrm{K}=0.22 \mathrm{nM}$

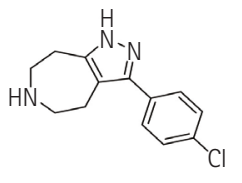

Azepine $5-\mathrm{HT}_{7} \mathrm{R}, \mathrm{K}=30 \mathrm{nM}$
Figure 2. Structures of selective $5-\mathrm{HT}_{7}$ receptor ligands.

drugs. Trazodone produced significant improvement in sleep parameters with increase in total sleep time (TST), sleep efficiency index, sleep continuity index, and SWS and reduction of the number of awakenings. Combined treatment with CBT and various medication for primary insomnia has not been shown to produce greater satisfaction with sleep complaints than single treatment of CBT [42]. Zavesicka et al. [42] have chosen trazodone to combine with CBT based on such previous research that it has feasibility for long-term use and positive effects on sleep architecture. Combined treatment with trazodone significantly increased SWS duration and TST in 20 patients with chronic primary insomnia, while this influence is not observed in the group of patients treated with CBT only [43]. Another potent 5- $\mathrm{HT}_{2 \mathrm{~A}}$ receptor antagonist, lumateperone (ITI-007) (Figure 1) is a new and atypical antipsychotic with strong affinity for dopamine $\mathrm{D}_{2}$ receptor and SERT. Lumateperone is characterized by the binding affinities to $5-\mathrm{HT}_{2 \mathrm{~A}}$ receptor $\left(\mathrm{K}_{\mathrm{i}} 0.54 \mathrm{nM}\right)$ and $\mathrm{D} 2$ receptor $\left(\mathrm{K}_{\mathrm{i}} 32 \mathrm{nM}\right)$ or SERT $\left(\mathrm{K}_{\mathrm{i}} 61\right.$ $\mathrm{nM}$ ), while binding affinities are relatively low at histaminergic $\mathrm{H} 1$, serotonin $5-\mathrm{HT}_{2 \mathrm{C}}$, and muscarinic receptors associated with side effects of antipsychotic drugs $[43,44]$. In addition, lumateperone induced SWS at low doses $(<0.2 \mathrm{mg} / \mathrm{kg}$ in rodents), and was considered to relieve insomnia without daytime sedation. As the dose is increased ( $>1.0 \mathrm{mg} / \mathrm{kg}$ in rodents), other drug targets such as dopamine $\mathrm{D}_{2}$ receptor and SERT are saturated by lumateperone with relieving symptoms related to schizophrenia or bipolar disorder. These data indicated that lower concentration of lumate- perone might have predominant $5-\mathrm{HT}_{2 \mathrm{~A}}$ receptor selectivity with moderate interaction with $\mathrm{D}_{2}$ receptor and SERT and that as doses of the drug is increased, additional pharmacological effect also emerged [43]. Though lumateperone interacts with $5-\mathrm{HT}_{2 \mathrm{~A}}, \mathrm{D}_{2}$ receptor and SERT in a dose dependent manner, it presents a unique pharmacology and influences neuropsychiatric and neurodegenerative diseases including sleep disturbances in neuropsychiatric diseases without off-target interaction and other side effects [45]. Davis et al. [46] proposed metabolic pathway in which lumateperone is mainly reduced to its secondary alcohol derivative (IC200131) by a ketone reductase and is converted to its N-desmethyl derivatives (IC200161) or its reduced derivative (IC200565) by cytochrome P450 3A4 (CYP3A4) and IC200131 can be converted back to lumateperone via CYP3A4. Pharmacological efficacy of the drug is driven by these active metabolites. The phase I, phase II, and phase III clinical trials of lumateperone have been completed, thus Intra-Cellular Therapies Inc., the developer of lumateperone, recently submitted the New Drug Application (NDA) to the U.S. FDA. In phase I studies, oral doses of lumateperone were administered to healthy volunteers and patients with schizophrenia, which were safe and had little adverse effects [45]. Based on brain receptor occupancy studies using positron emission tomography, 60-120 mg doses were selected for further investigation and in Phase II B study, $60 \mathrm{mg}$ dose of lumateperone considerably reduced insomnia, dementia, and symptoms related to schizophrenia. In Phase III clinical trials, lumateperone showed superior antipsychotic efficacy for treatment of schizophrenia compared with placebo and indicated improved social functioning measured in the Personal and Social Performance Scale compared to placebo [47]. Lumateperone currently received Fast Track designation from the FDA in November 2017 for the treatment of schizophrenia. Intra-Cellular Therapies Inc. announced that the company has completed the rolling submission of NDA to the U.S. FDA for lumateperone. The NDA submission is supported by data from 20 clinical trials and more than 1,900 subjects exposed to lumateperone [48].

\section{5-HT 7 RECEPTOR FOR INSOMNIA}

5- $\mathrm{HT}_{7}$ receptor is the last 5-HT receptor subtype discovered and has been cloned from various species such as human, rat, rabbit, and guinea pig [49-52]. 5- $\mathrm{HT}_{7}$ receptor is positively coupled to adenylyl cyclase via activation of $\mathrm{G}_{\mathrm{S}}$, inducing an intracellular increase of cAMP $[49,50]$. According to immunohistochemistry and autoradiography, $5-\mathrm{HT}_{7}$ receptor are distributed in hypothalamus, pontine nuclei, DRN, and hippocampus involved in the regulation of the sleep-wake cycle including SWS, REM sleep, and $\mathrm{W}$ [49-52]. 5- $\mathrm{HT}_{7}$ receptor in the DRN are localized to GABAergic neurons not to serotonergic neurons, suggesting that it does not subserve an autoreceptor fuction [53]. In the 5- $\mathrm{HT}_{7}$ receptor knock-out mice, $5-\mathrm{HT}_{7}^{-1-}$ mice, total time and episode frequency of REM sleep are reduced than wild type, $5-\mathrm{HT}_{7}^{+/+}$ mice with no difference between genotypes in parameters of $\mathrm{W}$ 
or SWS [23]. Microinjection of a $5-\mathrm{HT}_{7}$ receptor antagonist, SB269970 (Figure 2) into the DRN increased W and reduced REM sleep and the number of REM periods compared with those of the control vehicle. Furthermore, systemic administration of SB269970 reduced the time spent in REM sleep and the number of REM sleep occurrences and increased the latency to REM sleep [54,55]. Excitatory 5-HT 7 receptors expressed by GABAergic cells is suppressed by microinjection of SB-269970 into the DRN, which leads to the reduction of GABAergic inhibition of 5-HT neuron and to the increase of 5-HT release at postsynaptic sites critical for the induction and maintenance of REM sleep, resulting in decrease of REM sleep [55]. This proposal is supported by previous studies that pretreatment with the GABA-A receptor agonist muscimol prevented the effect of SB-269970 on REM sleep [56]. Monti et al. [25] demonstrated that the microinjection of LP-44 (Figure 2), a 5- $\mathrm{HT}_{7}$ receptor agonist into the DRN induced the reduction of REM sleep and the number of REM periods. Similar results were observed in microinjection of SB-269970 and pretreatment with SB-269970 inhibited the effects of LP-44 on REM sleep [25]. Thus, they tentatively proposed that since numerous GABAergic neurons in the DRN contribute to long projections reaching the laterdorsal and pedunculopontine tegmental nuclei (LDT/PPT) containing cholinergic neurons, the activation by LP-44 of projection GABAergic neurons could cause inhibition of cholinergic neurons in the LDT/PPT, resulting in reduction of REM sleep [25]. Administration of JNJ-18038683, a 5-HT receptor antagonist into rats dose-dependently suppressed REM sleep and the duration of REM sleep and significantly increased REM sleep latency after the treatment without changes in NREM sleep [26]. This group also found that JNJ-18038683 enhanced REM suppression induced by citalopram both in rodents and in humans [26]. In addition, clinical evaluation has shown that JNJ18038683 significantly increased the time of REM sleep episode compared to placebo and reduced total REM sleep time. These data demonstrated that the effect of $5-\mathrm{HT}_{7}$ receptor blockade induced by JNJ-18038683 on REM sleep is translated from rodents to humans [26,57]. JNJ-18038683 is now undergoing a phase II clinical trials as adjunctive treatment to improve cognition impairment and to alleviate depressive symptoms in stable bipolar patients [57]. Kim et al. [27] have discovered Azepine (3-(4-chlorophenyl)-1,4,5,6,7,8-hexahydropyrazolo[3,4-d]azepine) as the $\beta$-arrestin biased ligand against $5-\mathrm{HT}_{7}$ receptor $[\mathrm{Ki} 30$ $\mathrm{nM}, \mathrm{IC}_{50}$ (G protein) 7,800 nM, EC $\mathrm{E}_{50}$ ( $\beta$-arrestin) $\left.162 \mathrm{nM}\right]$ through the functional selectivity tests. They also carried out electroencephalogram experiment to investigate a correlation between $\beta$-arrestin biased agonism of Azepine and NREM/REM sleep. Azepine produced increase of NREM sleep duration and reduction of REM sleep duration, while the balanced antagonist SB-269970 decreased REM sleep duration without change of NREM sleep. Although they need more experimental data to identify the correlation between biased ligand and sleep, they suggested that $\beta$-arrestin activity of $5-\mathrm{HT}_{7}$ receptor might modulate NREM sleep patterns based on those results.

\section{CONCLUSIONS}

In this review, we have explored and investigated the role of 5-HT receptors and effects of related drugs or drug candidates on insomnia. We studied among those 5-HT receptors, especially, $5-\mathrm{HT}_{2 \mathrm{~A}}$ receptor and $5-\mathrm{HT}_{7}$ receptor with the possibility of treating insomnia. $5-\mathrm{HT}_{2 \mathrm{~A}}$ receptor antagonist, trazodone promoted sleep onset and is effective for sleep maintenance by increasing SWS and decreasing night-time awakenings with no significant changes in other sleep parameters. Lumateperone, recently developed as $5-\mathrm{HT}_{2 \mathrm{~A}}$ receptor antagonist, indicated improvement in sleep quaility in phase II B clinical trials, received Fast Track designation from the FDA in November 2017, and currently submitted NDA to the U.S. FDA. This review article focused on administration of agonists or antagonists against $5-\mathrm{HT}_{7}$ receptor, representatively SB-269970, JNJ-18038683, and LP-44 into DRN which altered sleep patterns in rats. These ligands reduced REM sleep and increased REM sleep latency without changes in W or SWS. Furthermore, Azepine has been discovered as $\beta$-arrestin biased agonist, which induced increase of NREM sleep duration and reduction of REMS duration. Taken together, 5-HT receptors has been involved in sleep and various drugs or drug candidates binding to 5-HT receptors could change sleep parameters, thus these findings from previous or current studies suggest that 5-HT receptors are promising of the treatment of insomnia and that there is an urgent need for further research about correlation between 5-HT receptors and insomnia.

\section{Acknowledgments}

This research is supported by the Original Technology Research Program (NRF-2016M3C7A1904344) funded by the National Research Foundation of Korea (NRF). And this work is additionally funded by the Korea Institute of Science and Technology (KIST) Institutional Program (2E29190 and 2E29222).

\section{Conflicts of Interest}

The authors have no potential conflicts of interest to disclose.

\section{Author Contributions}

Conceptualization: Hyunah Choo. Data curation: Jieon Lee. Formal analysis: Jieon Lee. Funding acquisition: Hyunah Choo. Investigation: Hyunah Choo. Methodology: Jieon Lee. Project administration: Hyunah Choo. Supervision: Hyunah Choo. Validation: Hyunah Choo. Writing-original draft: Jieon Lee. Writing-review \& editing: Hyunah Choo, Jieon Lee.

\section{ORCID iDs}

Hyunah Choo (D)

https://orcid.org/0000-0002-3545-2678

Jieon Lee (D)

https://orcid.org/0000-0003-3004-3725 


\section{REFERENCES}

1. Buysse DJ. Insomnia. JAMA 2013;309:706-716.

2. Buysse DJ, Rush AJ, Reynolds CF 3rd. Clinical management of insomnia disorder. JAMA 2017;318:1973-1974.

3. Baglioni C, Regen W, Teghen A, Spiegelhalder K, Feige B, Nissen C, et al. Sleep changes in the disorder of insomnia: a meta-analysis of polysomnographic studies. Sleep Med Rev 2014;18:195-213.

4. American Psychiatric Association. Diagnostic and statistical manual of mental disorders: DSM-4. Washington, DC: American Psychiatric Publishing; 2000

5. American Academy of Sleep Medicine. International classification of sleep disorders: diagnostic and coding manual (2nd ed). Westchester: American Academy of Sleep Medicine; 2005

6. American Psychiatric Association. Diagnostic and statistical manual of mental disorders: DSM-5. Arlington: American Psychiatric Publishing; 2013

7. Passarella S, Duong MT. Diagnosis and treatment of insomnia. Am J Health Syst Pharm 2008;65:927-934.

8. Khurshid AK. A review of changes in DSM-5 sleep-wake disorders. Psychiatr Times. September 30, 2015. Available at: https://www.psychiatrictimes. com/special-reports/review-changes-dsm-5-sleep-wake-disorders. Accessed November 28, 2018.

9. Roth T, Jaeger S, Jin R, Kalsekar A, Stang PE, Kessler RC. Sleep problems, comorbid mental disorders, and role functioning in the national comorbidity survey replication. Biol Psychiatry 2006;60:1364-1371.

10. Breslau N, Roth T, Rosenthal L, Andreski P. Sleep disturbance and psychiatric disorders: a longitudinal epidemiological study of young adults. Biol Psychiatry 1996;39:411-418.

11. Dujardin S, Pijpers A, Pevernagie D. Prescription drugs used in insomnia. Sleep Med Clin 2018;13:169-182.

12. Morin CM, Benca R. Chronic insomnia. Lancet 2012;379:1129-1141.

13. National Institutes of Health. National Institutes of Health State of the Science Conference statement on manifestations and management of chronic insomnia in adults, June 13-15, 2005. Sleep 2005;28:1049-1057.

14. Vanover KE, Davis RE. Role of 5-HT2A receptor antagonists in the treatment of insomnia. Nat Sci Sleep 2010;2:139-150.

15. Idzikowski C, Mills FJ, Glennard R. 5-Hydroxytryptamine-2 antagonist increases human slow wave sleep. Brain Res 1986;378:164-168.

16. Monti JM. Serotonin control of sleep-wake behavior. Sleep Med Rev 2011;15: 269-281.

17. Hoyer D, Hannon JP, Martin GR. Molecular, pharmacological and functional diversity of 5-HT receptors. Pharmacol Biochem Behav 2002;71:533554.

18. Sørensen E, Grønli J, Bjorvatn B, Bjørkum A, Ursin R. Sleep and waking following microdialysis perfusion of the selective 5-HT1A receptor antagonist p-MPPI into the dorsal raphe nucleus in the freely moving rat. Brain Res 2001; 897:122-130.

19. Boutrel B, Franc B, Hen R, Hamon M, Adrien J. Key role of 5-HT1B receptors in the regulation of paradoxical sleep as evidenced in 5-HT1B knock-out mice. J Neurosci 1999;19:3204-3212.

20. Stahl SM. Mechanism of action of trazodone: a multifunctional drug. CNS Spectr 2009;14:536-546.

21. Davis RE, Correll CU. ITI-007 in the treatment of schizophrenia: from novel pharmacology to clinical outcomes. Expert Rev Neurother 2016;16:601-614.

22. Hagan JJ, Price GW, Jeffrey P, Deeks NJ, Stean T, Piper D, et al. Characterization of SB-269970-A, a selective 5-HT(7) receptor antagonist. Br J Pharmacol 2000;130:539-548.

23. Hedlund PB, Danielson PE, Thomas EA, Slanina K, Carson MJ, Sutcliffe JG. No hypothermic response to serotonin in 5-HT7 receptor knockout mice. Proc Natl Acad Sci U S A 2003;100:1375-1380.

24. Leopoldo M, Berardi F, Colabufo NA, Contino M, Lacivita E, Niso M, et al. Structure-affinity relationship study on N-(1,2,3,4-tetrahydronaphthalen1-yl)-4-aryl-1-piperazinealkylamides, a new class of 5-hydroxytryptamine7 receptor agents. J Med Chem 2004;47:6616-6624.

25. Monti JM, Leopoldo M, Jantos H. The serotonin 5-HT7 receptor agonist LP44 microinjected into the dorsal raphe nucleus suppresses REM sleep in the rat. Behav Brain Res 2008;191:184-189.

26. Bonaventure P, Dugovic C, Kramer M, De Boer P, Singh J, Wilson S, et al. Translational evaluation of JNJ-18038683, a 5-hydroxytryptamine type 7 re- ceptor antagonist, on rapid eye movement sleep and in major depressive disorder. J Pharmacol Exp Ther 2012;342:429-440.

27. Kim Y, Kim H, Lee J, Lee JK, Min SJ, Seong J, et al. Discovery of $\beta$-arrestin biased ligands of 5-HT(7)R. J Med Chem 2018;61:7218-7233.

28. Sharpley AL, Solomon RA, Fernando AI, da Roza Davis JM, Cowen PJ. Doserelated effects of selective 5-HT2 receptor antagonists on slow wave sleep in humans. Psychopharmacology (Berl) 1990;101:568-569.

29. Cornea-Hébert V, Riad M, Wu C, Singh SK, Descarries L. Cellular and subcellular distribution of the serotonin 5-HT2A receptor in the central nervous system of adult rat. J Comp Neurol 1999;409:187-209.

30. Monti JM. Serotonin 5-HT(2A) receptor antagonists in the treatment of insomnia: present status and future prospects. Drugs Today (Barc) 2010;46: 183-193.

31. Popa D, Léna C, Fabre V, Prenat C, Gingrich J, Escourrou P, et al. Contribution of 5-HT2 receptor subtypes to sleep-wakefulness and respiratory control, and functional adaptations in knock-out mice lacking 5-HT2A receptors. J Neurosci 2005;25:11231-11238.

32. Dugovic C, Van den Broeck WAE. Sleepwakefulness alterations produced by the putative serotonin 5 -HT1c agonist m-chlorophenylpiperazine in the rat. Sleep Res 1991;20A:129-134.

33. Montgomery I, Oswald I, Morgan K, Adam K. Trazodone enhances sleep in subjective quality but not in objective duration. Br J Clin Pharmacol 1983;16: 139-144.

34. Mouret J, Lemoine P, Minuit MP, Benkelfat C, Renardet M. Effects of trazodone on the sleep of depressed subjects: a polygraphic study. Psychopharmacology (Berl) 1988;95 Suppl:S37-S43.

35. Schweitzer PK, Curry DT, Eisenstein RD, Walsh JK. Pharmacological treatment of insomnia. In: Attarian HP, Schuman C, editors. Clinical handbook of insomnia (2nd ed). Totowa: Humana Press Inc, 2010, p. 297-316.

36. Nierenberg AA, Adler LA, Peselow E, Zornberg G, Rosenthal M. Trazodone for antidepressant-associated insomnia. Am J Psychiatry 1994;151:1069-1072.

37. Roth AJ, McCall WV, Liguori A. Cognitive, psychomotor and polysomnographic effects of trazodone in primary insomniacs. J Sleep Res 2011;20:552558.

38. Muratatorio A, Maggini C, Coccanna G, Guazelli. M. Polygraphic study of the all night sleep pattern in neurotic and depressed patients treated with trazodone. In: Ban TA, Silvestrini B, editors. Trazodone: new avenues in psychopharmaco-therapy. Proceedings of the 1st International Symposium, Montreal 1973 (Modern trends in pharmacopsychiatry, Vol. 9) . Basel: S. Karger, 1974, p. 182-189.

39. Paterson L, Nutt DJ, Durant C, Wilson SJ. Efficacy of trazodone in primary insomnia: a double-blind randomized placebo controlled polysomnographic study. Eur Neuropsychopharm 2009;19(Suppl 3):S385-S386.

40. Generali JA, Cada DJ. Trazodone: insomnia (adults). Hosp Pharm 2015;50: 367-369.

41. Kaynak H, Kaynak D, Gözükirmizi E, Guilleminault C. The effects of trazodone on sleep in patients treated with stimulant antidepressants. Sleep Med 2004;5:15-20.

42. Zavesicka L, Brunovsky M, Horacek J, Matousek M, Sos P, Krajca V, et al. Trazodone improves the results of cognitive behaviour therapy of primary insomnia in non-depressed patients. Neuro Endocrinol Lett 2008;29:895901.

43. Snyder GL, Vanover KE, Zhu H, Miller DB, O’Callaghan JP, Tomesch J, et al. Functional profile of a novel modulator of serotonin, dopamine, and glutamate neurotransmission. Psychopharmacology (Berl) 2015;232:605-621.

44. Lieberman JA, Davis RE, Correll CU, Goff DC, Kane JM, Tamminga CA, et al. ITI-007 for the treatment of schizophrenia: a 4-week randomized, doubleblind, controlled trial. Biol Psychiatry 2016;79:952-961.

45. Mendelson WB. A review of the evidence for the efficacy and safety of trazodone in insomnia. J Clin Psychiatry 2005;66:469-476.

46. Davis RE, Hendrick JP, Zhang L, Yao W, Wennogle L, Zhu H, et al. Poster \#S78: The novel pharmacology of ITI-007 is enhanced and extended by its metabolic back conversion from IC200131. Schizophrenia Res 2014;153(Suppl 1):S116.

47. Vanover KE, Davis RE, O'Gorman C, Saillard J, Weingart M, Mates S. The clinical development of lumateperone (ITI-007) for the treatment of schizophrenia. Schizophrenia Bull 2017;43(Suppl 1):S16.

48. Intra-cellular therapies completes submission of new drug application for lumateperone for treatment of schizophrenia. Available at: http://ir.intracel- 
lulartherapies.com/news-releases/news-release-details/intra-cellular-therapies-completes-submission-new-drug. Accessed November 20, 2018.

49. Hedlund PB, Huitron-Resendiz S, Henriksen SJ, Sutcliffe JG. 5-HT7 receptor inhibition and inactivation induce antidepressantlike behavior and sleep pattern. Biol Psychiatry 2005;58:831-837.

50. Lovenberg TW, Baron BM, de Lecea L, Miller JD, Prosser RA, Rea MA, et al. A novel adenylyl cyclase-activating serotonin receptor (5-HT7) implicated in the regulation of mammalian circadian rhythms. Neuron 1993;11:449-458.

51. Ruat M, Traiffort E, Leurs R, Tardivel-Lacombe J, Diaz J, Arrang JM, et al. Molecular cloning, characterization, and localization of a high-affinity serotonin receptor (5-HT7) activating cAMP formation. Proc Natl Acad Sci U S A 1993;90:8547-8551.

52. Duncan MJ, Short J, Wheeler DL. Comparison of the effects of aging on 5HT7 and 5-HT1A receptors in discrete regions of the circadian timing system in hamsters. Brain Res 1999;829:39-45.

53. Duncan MJ, Grear KE, Hoskins MA. Aging and SB-269970-A, a selective 5-HT7 receptor antagonist, attenuate circadian phase advances induced by microinjections of serotonergic drugs in the hamster dorsal raphe nucleus. Brain Res 2004;1008:40-48.

54. Monti JM, Leopoldo M, Jantos H, Lagos P. Microinjection of the 5-HT7 receptor antagonist SB-269970 into the rat brainstem and basal forebrain: sitedependent effects on REM sleep. Pharmacol Biochem Behav 2012;102:373380.

55. Monti JM, Jantos H. Effects of the 5-HT(7) receptor antagonist SB-269970 microinjected into the dorsal raphe nucleus on REM sleep in the rat. Behav Brain Res 2006;167:245-250.

56. Ford B, Holmes CJ, Mainville L, Jones BE. GABAergic neurons in the rat pontomesencephalic tegmentum: codistribution with cholinergic and other tegmental neurons projecting to the posterior lateral hypothalamus. J Comp Neurol 1995;363:177-196.

57. Modica MN, Lacivita E, Intagliata S, Salerno L, Romeo G, Pittalà V, et al. Structure-activity relationships and therapeutic potentials of 5-HT7 receptor ligands: an update. J Med Chem 2018;61:8475-8503. 